\title{
Justification of optimal design and technological parameters of needle discs of the combined working body
}

\author{
Alexander M. Petrov, Sergey A. Ivanayskiy*, Mikhail A. Kanaev, Oleg M. Parfyonov, and Maxim S. Ivanayskiy \\ Samara State Agrarian University, Samara 446442, Russia
}

\begin{abstract}
The aim of the research is to improve soil tillage quality using combined working bodies in surface cultivation. There are various designs of combined tillage units including passive cultivators and active rotor-tooth working bodies cultivating land. However, an analysis of design and technological parameters of modern cultivators shows that they have a cumbersome design, required much metal and their quality indicators do not meet soil cultivation requirements. The article presents results of the studies on the influence of geometric and technological parameters of an additional battery of needle discs on land tillage quality. Using the research results, the land tillage has been improved and combined working bodies have been developed.
\end{abstract}

\section{Introduction}

Surface tillage is required to eliminate weeds and loose soil when preparing it for cultivating various crops. Loosening and simultaneous mixing of plant residues preserve and accumulate moisture in the surface layer [1, 2].

The mulching surface layer contributes to the formation and preservation of nutrients required for the growth of plants. In addition, loosening reduces evaporation of moisture and creates favorable conditions for sowing and planting [3-5]

It is necessary to exclude excessive clumping and soil heterogeneity by using rotary working bodies.

Surface tillage should be performed across or at an angle from previous passages at a speed of $2.5 \ldots 3.0 \mathrm{~m} / \mathrm{s}$ (9 ... $12 \mathrm{~km} / \mathrm{h})$.

Cultivation before sowing is carried out with an accuracy of $\pm 0.01 \mathrm{~m}$ to the depth of the location of seeds, while it is necessary to form a dense and even bed for seeds in the subsurface layer. It is necessary to form a mulching layer with a minimum combing within the range of $0.03 \ldots 0.04 \mathrm{~m}$. In this regard, harrowing is often carried out simultaneously with cultivation using passive tooth harrows. [6, 7]

Among the various working bodies with which cultivators are equipped for continuous tillage, one can distinguish the basic, so to say "classic" ones: lancet paws with a working width of 80 to $330 \mathrm{~mm}$ and a cutting angle of $18 \ldots 28^{\circ}$; sections of tooth harrows or harrows with spring teeth; various types of press rollers: bar, plate, ring, etc.
The lancet paw is currently the most common cutting organ of cultivators. It performs two functions: cutting weeds and loosening the soil. Also, when it is working, the pruned layer is displaced, which excludes the survival of the pruned weeds. However, during the operation of the lancet paw with a crumbling angle, the bottom of the groove is exposed, moist soil is carried out to the day surface, the soil surface after treatment becomes ridge, the evaporation area expands, which is extremely undesirable, especially in arid regions. These factors are significant disadvantages.

The pendant suspension to the machine frame is radial, also the pylon racks or ridges are usually spring loaded, which protects the working body from breakage when running into a stone. However, this leads to paw vibration in the soil during operation and, as a result, to uneven seed bed in the case of pre-sowing treatment. In addition, the radial suspension in combination with the support wheels leads to significant variability in the depth of processing. When the wheels get into the grooves, the paws are deepened, and when they hit the bumps, the working bodies are swept out, which is absolutely not allowed by agricultural requirements. It is worth noting that on these types of racks, there is a strong hovering of vegetation. Currently, manufacturers of tillage machines have almost completely abandoned this type of racks, switching to s-shaped racks of lancet paws. Such racks do not require the installation of a spring, therefore, the device for attaching them to the cultivator frame is simplified; the trimmed vegetation does not hover on them so much. However, it should be noted that they are quite expensive in production and when colliding with a large stone, they are easily deformed, becoming unusable.

Corresponding author: isa.7777@inbox.ru 
Currently, some manufacturers have refused to equip their machines with flat tooth harrows, opting for sections of harrows with spring teeth. This is partly justified, since spring teeth crumble lumps of soil much more efficiently than teeth of flat harrows, less weeds hover on them.

However, they are more difficult to manufacture and more often fail when they collide with stones and other obstacles when working and when transporting the cultivator.

Recently, lancet needle rollers are usually placed next to lancet paws on cultivators. They are to perform the function of crumbling soil lumps and leveling the surface of the field after treatment.

Today, there are many manufacturers that produce a huge number of tillage cultivators. Most of the designs include separate blocks of loosening legs located in several rows, passive tooth harrows or packer rollers which significantly increases the size and weight of the tool.

Taking into account the shortcomings of existing combined units, a soil Samara SAU developed a cultivator based on the KBM cultivator. The cultivator is equipped with advanced combined working bodies with rotary cultivators. $[8,9]$

The use of combined working bodies will make it possible to improve characteristics of the tool, as well as reduce production costs and increase competitiveness of products.

\section{Materials and methods}

One of the main tasks of surface tillage is formation of favorable conditions in the tilled layer for the germination of seeds, further development of cultivated plants and moisture preservation. The solution to this task will be achieved by creating well-cut soil to the depth of sowing seeds with a carefully leveled surface and mixed plant residues acting as a mulching layer, which will contribute to the accumulation and preservation of moisture, even germination and further development of cultivated plants. [10]

The working process of the combined working body to create soil with a level surface and mixed plant residues acting as a mulching layer is shown in Figure 1.

Initially, the surface layer is cut, loosened and mixed at a sowing depth. The dense bed for seeds is formed (Figure 1). Then the soil and plant residues are mixed creating a mulched layer and a leveled surface (Figure 1) using rotary working bodies.

Such preparation of the surface layer for sowing will ensure uniform distribution of seed material both in depth and along the length of the seeds in a row, which will contribute to the formation of the same nutritional area for cultivated plants and even seedlings in the initial growing season.

Plant residues distributed throughout the depth of the mulching layer will provide increased protection of the surface of the treated soil layer from evaporation of moisture necessary for the growth of cultivated plants.

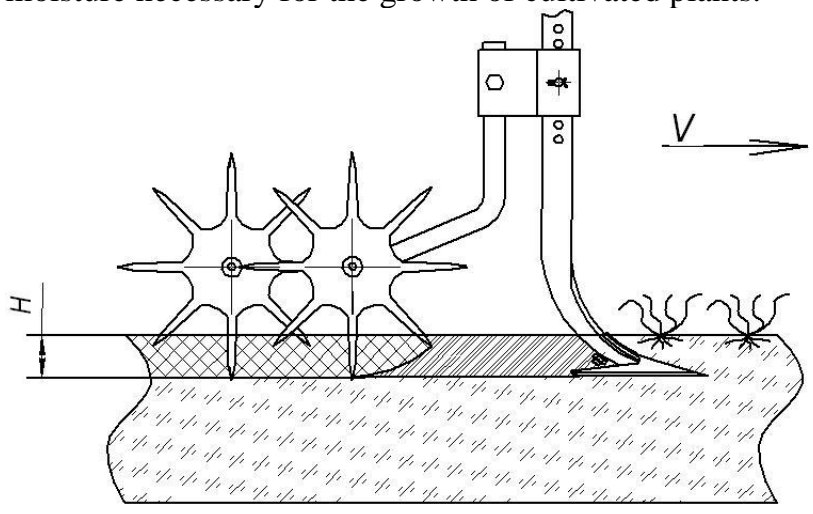

Fig. 1. The technological process of surface tillage

To perform the above working process, a combined working body was designed and manufactured. It includes lancet paws mounted on a plug-in module and needle-disk batteries mounted with a special bracket located on a rack above the lancet foot.

The vertical position of the needle-disk battery can be changed by rearranging the locking pin on the rack holes. This mutual movement of the needle discs and lancet paws makes it possible to establish the optimal depth for each type of working bodies.

The block-modular cultivator with combined working bodies (Figure 2) contains supporting frame 1 with supporting and copying wheels 6 , a hitch for aggregation with tractor 2 , combined working bodies in the form of lancet paws with needle discs mounted behind each stand along the entire working width on replaceable module 3 ; the cultivators are mounted directly on the lancet leg; plank-tooth equalizer 4 is located in front of rotary harrow 5. The depth has to be adjusted.

The technological process of the cultivator with combined working bodies is performed in the following sequence.

Block-modular cultivator KBM equipped with combined working bodies is transferred from the transport to the working position using the hydraulic cylinders of the machine and the tractor's hydraulic system.

Depending on the condition and the type of soil, the cultivator must be mounted using supporting-copying wheels to the optimum depth of the lancet paws. It should be adjusted using a special mounting bracket.

During the movement of the unit along the field, lancet paws cut and crumble the soil layer to a specified depth with the formation of a dense bed for seeds, at the same time cutting the rhizomes of weeds and mixing the stubble residues in the surface layer, creating a mulching layer for accumulating and retaining moisture.

Following are the rotary working bodies mixing the soil with plant debris and creating a mulched layer with a carefully leveled surface. Thus, with fine tillage, a qualitatively prepared surface soil layer is created. 


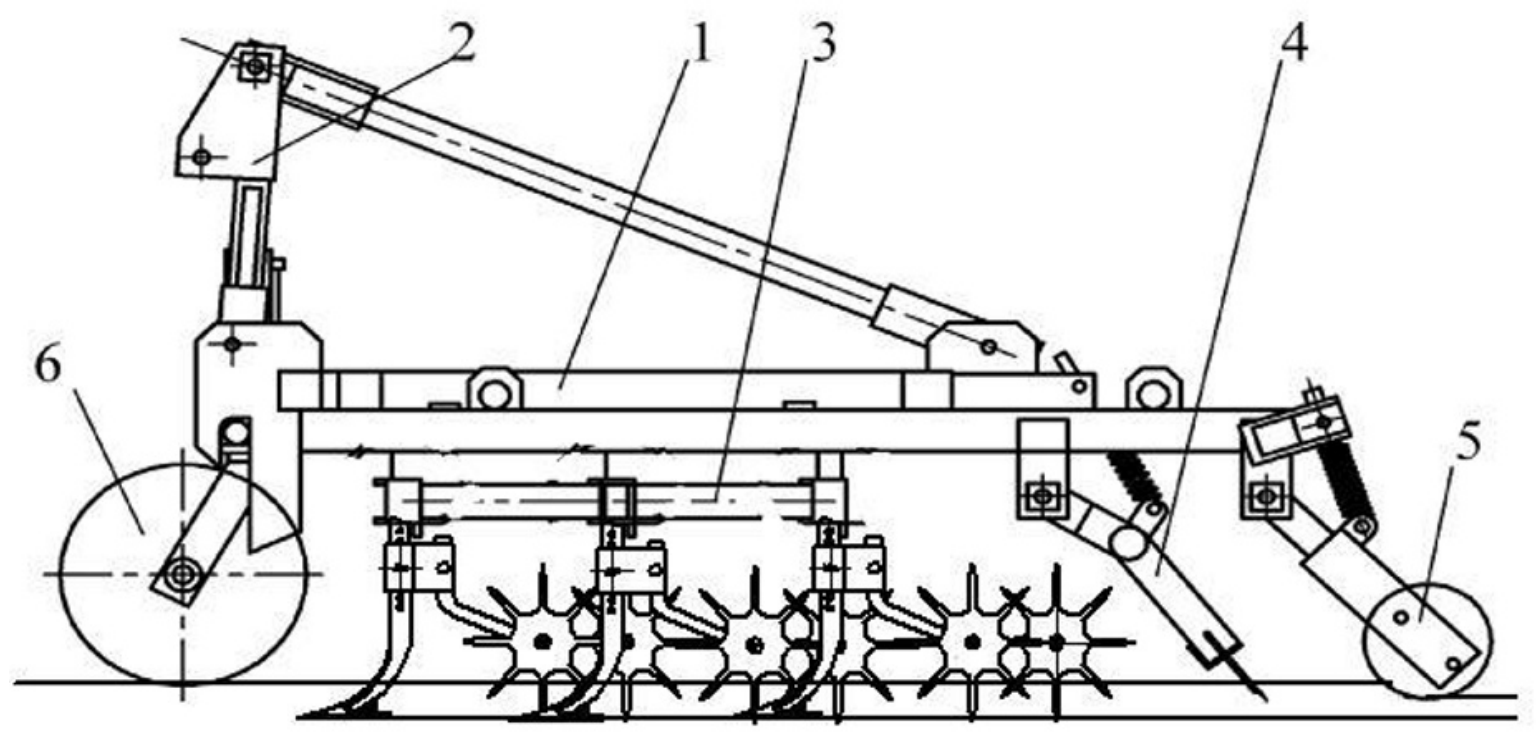

Fig. 2. Block-modular cultivator equipped with combined working bodies: 1 - carrier frame; 2 - attachment; 3 - replaceable module lancet paws with needle discs; 4 - plank-tooth equalizer; 5 - rotary harrow (roller); 6 - supporting copy wheels

The results of theoretical and experimental studies made it possible to develop an experimental tillage implement, consisting of a KBM type modular cultivator equipped with combined working bodies for surface tillage, which was aggregated with a tractor of traction class 3 in order to justify the geometric parameters and the location of the needle disks battery during the technological process.

When conducting experiments in order to justify geometric parameters and location of the needle-disk battery, a field section that has characteristics typical of the Middle Volga region was selected: the type of soil - medium-loamy ordinary chernozem, finely lumpy, mild microrelief.

To determine the degree of influence of the geometric and technological parameters of the operation of an additional battery of needle discs on the quality of presowing tillage, experimental studies were conducted to substantiate the distance between the needle discs, the length of the needles and the running depth of the needle working bodies. These studies were carried out at a constant unit speed of $3.6 \mathrm{~m} / \mathrm{s}$.

To justify the length of the needles, measurements were carried out to determine tillage stability by depth. According to the measurement data, the standard deviation of the value was determined. In this case, the permissible measurement error was $\pm 0.1 \mathrm{~cm}$.

It was found that with an increase in the length of the needles, there is a constant change in stability of the stroke along the depth of the combined working body (Figure 3). This is due to the fact that the length of the needles affects the diameter of the needle disk. When the length is $0.1 \mathrm{~m}$ due to a reduced diameter, the rotational speed increases (its decrease causes an unreasonable loss of productivity). The increased frequency of rotation causes the ejection of moist soil layers to the surface which causes poor evenness of the soil surface and a decrease in the stability index of the tillage depth.

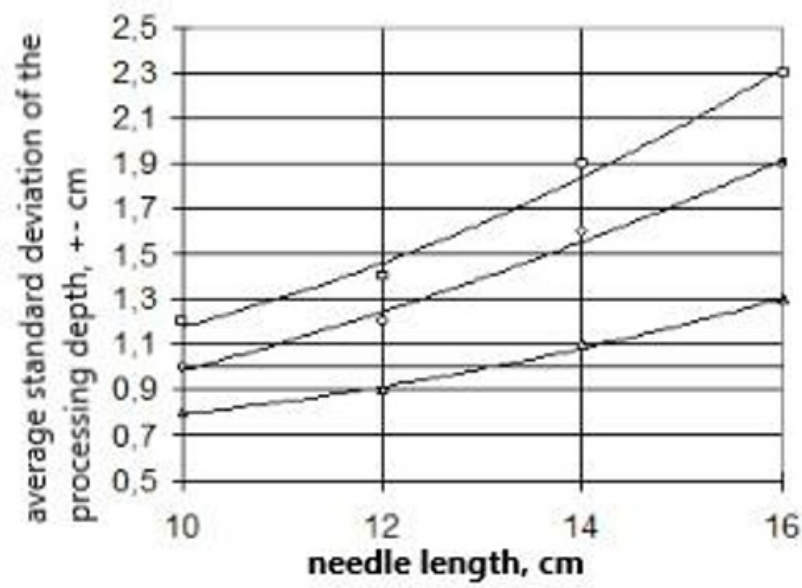

Fig. 3. Dependence of the standard deviation of the processing depth on the length of the needles. $\Delta$ - the distance between the needle discs is $0.07 \mathrm{~m}, \mathrm{o}-$ the distance between the needle discs is $0.06 \mathrm{~m},-$ - - the distance between the needle discs is $0.05 \mathrm{~m}$.

An increase in the length of the needles to $0.14 \mathrm{~m}$ increases the distance between the needles at the point of contact of the needle disk with the soil; in this case, highquality tillage is not performed over the entire cultivated area. Only the length of the needles equal to $0.12 \mathrm{~m}$ ensures the tillage depth of the working body in accordance with the agrotechnical requirements for surface tillage machines.

Determining the dependence of the change in the stability of the stroke along the depth of the combined working body on the distance between the racks of the 
pointed arm and the battery of needle disks (Figure 4) was carried out with fixing the distance between the needle disks at three levels: $0.07 \mathrm{~m}, 0.06 \mathrm{~m}$ and $0.05 \mathrm{~m}$. In all versions of the experiments, the distance between the racks varied from 0.1 to $0.25 \mathrm{~m}$ with a pitch of $0.05 \mathrm{~m}$. With an increase in the distance between the racks of the lancet paw and the battery of needle discs by $0.05 \mathrm{~m}$, the stability of movement along the depth of the combined working body decreases from 10 to 12.5 percent. This indicates a significant effect of changes in the distance between the racks of the lancet paw and the battery of needle discs on the stability of movement along the depth of the combined working body.

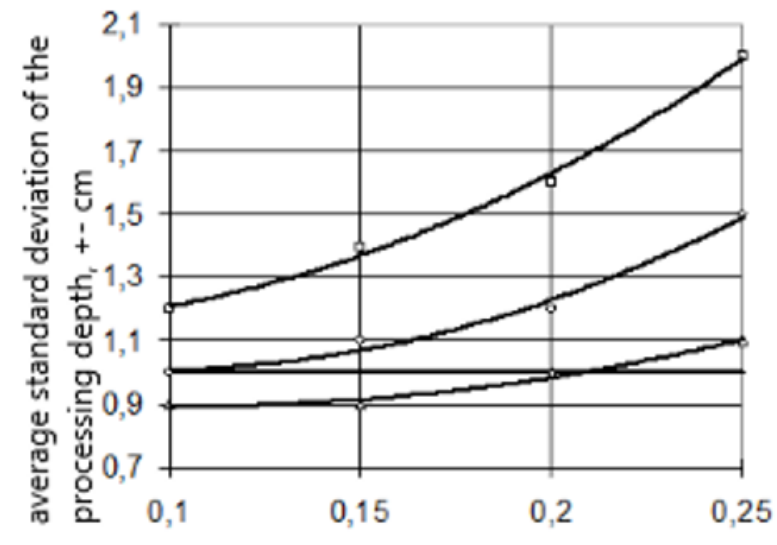

location of the needle disk batteries, $m$

Fig. 4. Dependence of the standard deviation of the processing depth on the location of the needle disk batteries. $\Delta-$ the distance between the needle discs is $0.07 \mathrm{~m}, \mathrm{o}-$ the distance between the needle discs is $0.06 \mathrm{~m},---$ the distance between the needle discs is $0.05 \mathrm{~m}$.

During the operation of the block-modular cultivator of KBM type equipped with combined working bodies for surface tillage, the topsoil is loosened to a set depth and effectively cut into the desired fractions. The quality of crumbling of the topsoil depends on the depth of processing.

In order to select the optimal distance between the needle discs, studies have been conducted to determine the effect of the distance between the needle discs on the ridging of the soil surface. The studies were conducted for the work of the working body at various processing depths of $0.04 \mathrm{~m}, 0.05 \mathrm{~m}$ and $0.06 \mathrm{~m}$.

The minimum ridging value was achieved at a minimum distance of $0.03 \mathrm{~m}$. However, at this distance, if the soil moisture in the layer of $0-10 \mathrm{~cm}$ is more than $15 \%$, stickiness of the needle disks can be observed. In the presence of large lumps of soil and plant residues, their clogging is observed. An increase in the distance between the needle discs to $0.05 \mathrm{~m}$ slightly changed the combing of the soil surface, however, the operation of the combined working body was stable without sticking and clogging of the needle discs. With a further increase in the distance to $0.06 \mathrm{~m}$, there is a significant increase in the ridging value.

In order to determine the degree of influence of the soil cultivation depth on quality of layer crumbling, field studies were conducted at a depth of $0.03 \mathrm{~m}, 0.04 \mathrm{~m}, 0.05$ and 0.06 $\mathrm{m}$, with operating speeds of $2.88 ; 3.24$ and $3.6 \mathrm{~m} / \mathrm{s}$.

Based on the data obtained, it can be noted that quality of soil crumbling at values of more than $80 \%$ is observed at a depth of 0.04-0.05 $\mathrm{m}$ with a maximum at a depth of $0.04 \mathrm{~m}$. This is due to the fact that at a greater depth, there are large soil layers to be cut using additional working bodies. The highest quality soil treatment by the combined working body occurs during the movement of needle discs at a depth of 0.04 $\mathrm{m}$, while the optimal value of the working speed is $v=3.6$ $\mathrm{m} / \mathrm{s}$, since in this case the quality of soil crumbling is above $80 \%$.

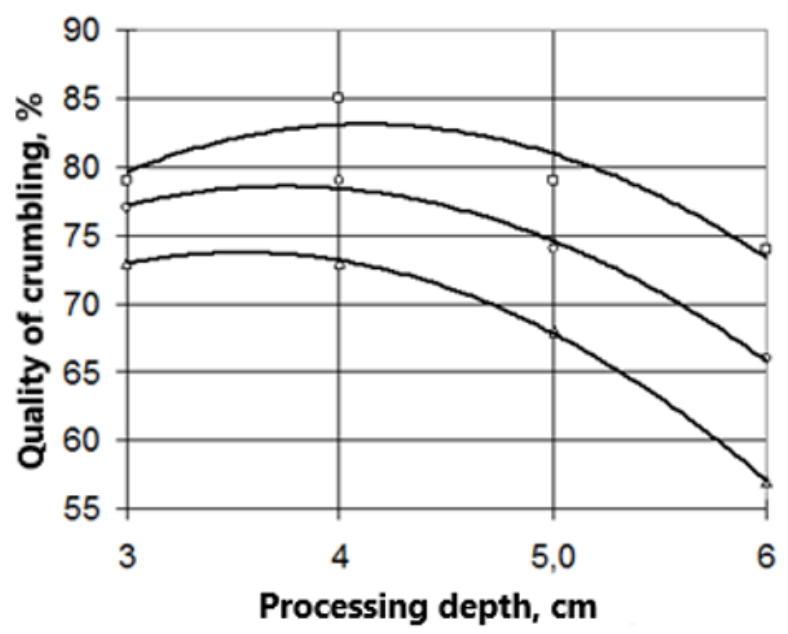

Fig. 5. Dependence of the quality of soil crumbling by the combined working body on the depth of processing. $\Delta$ - working speed 2.88 $\mathrm{m} / \mathrm{s}, \mathbf{O}$ - working speed $3.24 \mathrm{~m} / \mathrm{s},{ }_{-}^{-}$- working speed $3.6 \mathrm{~m} / \mathrm{s}$

\section{Results}

Thus, improved surface tillage includes cutting, trimming and mixing of the soil layer to the specified soil depth and mixing the soil and plant residues to create a mulched layer and a thoroughly leveled surface using rotary working bodies. Combined working bodies in the form of lancet paws with needle discs were developed and their design parameters were experimentally justified. To ensure agrotechnical ridging requirements at various working depths of the combined working body, the distance between the needle discs must be equal to $0.05 \mathrm{~m}$. This mutual arrangement of the needle discs will allow us to obtain the size of the ridges equal to less than $0.02 \mathrm{~m}$.

The results of measuring stability of the movement along the depth of the combined working body, depending on the distance between the racks of the pointed arm and the battery of the needle discs, showed that with an increasing distance between the racks, stability of the movement decreases.

The highest quality soil tillage using the combined working body can be achieved during the movement of the needle discs at a depth of $0.04 \mathrm{~m}$, while the optimal value of the working speed is $v=3.6 \mathrm{~m} / \mathrm{s}$, since soil crumbling quality is over $80 \%$.

It can be concluded that batteries of the needle discs should be located as close as possible to the rack of the 
cultivator paw which will correspond to a distance of $0.1 \mathrm{~m}$. This arrangement will contribute to the self-cleaning of the passive working body from weeds.

This combined working body can be used for almost any soil cultivating tool. The needle discs installed behind the working body stand have an intense pull-rotational effect on soil leveling and clod crushing. This working body is not clogged by sticky soil and plant residues. Weeds are combed out and carried to the soil surface.

\section{Conclusion}

The optimal design parameters of the needle disk battery are as follows: the needle length is $0.1 \mathrm{~m}$, as it ensures the working depth of the working body in accordance with agrotechnical requirements for surface tillage tools; the distance between the racks of the pointed foot and the needle disk battery should be $0,1 \mathrm{~m}$ at a working speed of $v$ $=3.24 \ldots 3.6 \mathrm{~m} / \mathrm{s}$ which ensures quality of soil crumbling exceeding $80 \%$. To ensure the minimum value of the soil surface combing, the distance between the needle discs should be $0.05 \mathrm{~m}$. This mutual arrangement of the needle discs will allow us to obtain the size of the ridges equal to less than $0.02 \mathrm{~m}$. Performance of the block-modular cultivator equipped with combined working bodies for surface tillage enhances the degree of seed germination.

\section{References}

1. N.L. Morris et al., The adoption of non-inversion tillage systems in the United Kingdom and the agronomic impact on soil, crops and the environment $-A$ review Soil and Tillage Research 108(1-2), 1-15 (2010)

2. C. Plaza et al., Physical, chemical, and biochemical mechanisms of soil organic matter stabilization under conservation tillage systems: a central role for microbes and microbial by-products in $C$ sequestration Soil Biology and Biochemistry 57, 124-134 (2013)

3. A. Jordán, L.M. Zavala, J. Gil, Effects of mulching on soil physical properties and runoff under semi-arid conditions in southern Spain Catena 81(1), 77-85 (2010)

4. J.A. Andrade, C.A. Alexandre, G. Basch, Effects of soil tillage and mulching on thermal performance of a Luvisol topsoil layer Foliae Oecologicae 37(1), 1-7 (2010)

5. D. Hillel, T.T. Kozlowski, Soil moisture and seed germination Water deficits and plant growth 3, 65-89 (2012)

6. K.H.D. Tiessen et al., Conventional and conservation tillage: Influence on seasonal runoff, sediment, and nutrient losses in the Canadian prairies $\mathrm{J}$. of Environmental Quality 39(3), 964-980 (2010)

7. C.K. Shedd, E.V. Collins, J.B. Davidson, Labor, power and machinery in corn production Bulletin 32(365), 1 (2017)

8. S.A. Ivanayskiy, A.N. Zotov, V.P. Berestov, Development of combined working bodies for land tillage Innovative Achievements of Science and Technology of the AI 392-396 (2018)

9. S.A. Ivanayskiy, O.M. Parfyonov, The working body for presowing tillage Actual problems of agricultural science and ways to solve them 364-366 (2016)

10. W. Xiukang, L. Zhanbin, X. Yingying, Effects of mulching and nitrogen on soil temperature, water content, nitrate- $N$ content and maize yield in the Loess Plateau of China Agricultural Water Management 161, 53-64 (2015) 